DOI: $10.20472 / T E .2016 .4 .1 .001$

\title{
INTERNATIONAL EXPERIENCE IN A NON-WESTERN COUNTRY, TEACHER HABITUS, AND LEVEL OF INCLUSION IN THE CLASSROOM
}

\section{ARDAVAN EIZADIRAD}

\begin{abstract}
:
One of the challenges with increasing diverse student populations in today's classrooms is figuring out ways to address the needs of all students. This paper explores the role of the teacher and his/her dispositions in creating an inclusive learning environment. This paper, through Pierre Bourdieu's interconnected theoretical concepts of habitus, capital, and field explores how an international experience in a non-Western country can help foster greater inclusion in a classroom setting. Autobiographical experiences of Bourdieu's time in Algeria as well as the author's international experiences in Iran and Barbados are presented as case studies. Overall, this paper seeks to advance the discussion on student disengagement beyond discourses of blame and towards exploring new avenues with potential for blossoming and unveiling of new understandings.
\end{abstract}

\section{Keywords:}

habitus, capital, field, Pierre Bourdieu, international experience, inclusion, student engagement, and teaching practices

JEL Classification: 124, 121, 129

\section{Authors:}

ARDAVAN EIZADIRAD, Ontario Institute for Studies in Education (OISE), University of Toronto, Canada, Email: ardavan.eizadirad@mail.utoronto.ca

\section{Citation:}

ARDAVAN EIZADIRAD (2016). International Experience in a Non-Western Country, Teacher Habitus, and Level of Inclusion in the Classroom . International Journal of Teaching and Education, Vol. IV(1), pp. 1-15., 10.20472/TE.2016.4.1.001 


\section{Introduction}

Today's classrooms represent diversity at its finest where students from all over the world who differ in race, religion, social class, gender, sexuality, ethnicity, and culture try to learn together with the guidance of a teacher. One of the complex challenges of dealing with such a diverse student population is figuring out multiple ways to address the needs of all students. Too often, dominant discourses problematize and place blame on students and their cultures for their failures and level of disengagement referred to as deficit thinking (hooks, 2003; Portelli \& Sharma, 2014). This paper approaches examination of student disengagement from a different angle, attempting to shift the gaze of the reader by examining the role of the teacher and his/her dispositions in creating an inclusive learning environment. The objective of this paper is to explore how an international experience in a non-Western country, specifically exposure to physical, psychological, and emotional challenges of being abroad can help implement inclusion within the teacher's classroom upon return from the experience. This exploration is framed through Pierre Bourdieu's interconnected theoretical concepts of habitus, capital, and field and its role in contributing to a teacher's pedagogical approach to teaching. The author's own international experiences in Iran and Barbados and Pierre Bourdieu's autobiographical experiences in Algeria are utilized as examples of authentic case studies serving as supportive evidence. Overall, the objective of this paper is to move the readers beyond linear modes of thinking -whether we should blame students or teachers for lack of disengagement within schools- and towards discussing new avenues that have potential to unveil new ideas, insights, and skills that can allow teachers to engage students and cultivate their potential by addressing their unique needs within a multicultural society.

\section{Theoretical Lens: Pierre Bourdieu's Habitus, Capital \& Field}

For Bourdieu, the concepts of habitus, capital, and field are interrelated as articulated in the form of a formula;

$[($ Habitus $)($ Capital) $]+$ Field $=$ Practice .

Maton (2008) deconstructs this formula by pointing out, "practice results from relations between one's dispositions (habitus) and one's position in a field (capital), within the current state of play of that social arena (field) (p. 51). Maton (2008) further expands on what habitus means,

Simply put, habitus focuses on our ways of acting, feeling, thinking, and being. It captures how we carry within us our histories, how we bring this history into our present circumstances, and how we then make choices to act in certain ways and 
not others. This is an ongoing and active process- we are engaged in a continuous process of making history, but not under conditions entirely of our own making (p. 52).

One of the significant aspects of habitus is that, as an evolving concept and a methodology, it analyzes and interprets the world in a relational manner taking into consideration history of individuals, their personal dispositions, influence of systematic structures and institutions, and the socio-cultural and political context of any given circumstance. This is reflected in the notion that "no two individual habituses are identical" (Reay, 2004, p. 434) since one's habitus is constantly being structured and simultaneously itself restructuring one's daily practice.

Although there has been extensive research done on student habitus (Horvat, 2001; Reay et al., 2001; Goldstein, 2003; Lareau \& Weininger, 2003) there is a lack of research on teacher habitus and its interconnectedness to formation of specific teaching pedagogies and practices. It is significant as a starting point to acknowledge that schools are not neutral and innocent, but rather they play an active role in perpetuating and reproducing oppression and oppressive practices; through inequitable power relations which contributes to Othering of certain social groups at the expense of providing privilege to others (hook, 2003;Dei 2000). Within the classroom, teachers have a substantial amount of power. Their dispositions and decisions in terms of classroom setup, pedagogy, course content and delivery of lessons, and selection of type and style of evaluations and assessments greatly contributes to what extent an inclusive learning environment is developed and fostered amongst students. Investing in creating an inclusive, non-judgemental learning environment is critical because it plays a pivotal role in engaging students and allowing them to take on an active role in their educational experiences. As bell hooks (2003) states, "The courage to teach is the courage to keep one's heart open in those very moments when the heart is asked to hold more than it is able so that teacher and students and subject can be woven into the fabric of community that learning, and living, require" (p. 19). On the other hand, lack of inclusion can discourage students to learn, lead to disengagement in class discussions, activities and events, not caring, and consequentially not putting in any or minimal effort to demonstrate mastering of content and skills learned.

International Experience

\section{Literature Review}

International experience in a non-Western country can help built inclusion in the classroom by disrupting and altering teacher habitus. But before further discussing what it means to disrupt or alter teacher habitus, we must take the time to identify some key 
terms and the socio-cultural context in which they are being applied. As Bourdieu emphasizes, it is important to avoid generalizations and instead be specific as a means of gaining understanding about a social phenomena or issue.

For the purpose of this paper, the word teacher(s) refers to educators in City of Toronto, Canada who teach in the public sector in urban schools and conduct classes in English under the Ontario Ministry of Education curriculum guidelines. The Toronto District School Board (TDSB) is the largest school board in Canada and one of the largest in North America consisting of nearly 600 schools serving approximately 232,000 students each year. The TDSB website (2015) gives a breakdown of its population which includes;

- 154,600 elementary students

- 76,000 high school students

- 1,300 international students

- 160,000 continuing education students (adult students)

- 24,843 students enrolled in immersion and extended French programs

- More than $80 \%$ of high school graduates accepted to university or college

- $27 \%$ of the student population born outside of Canada

- $43 \%$ of the student population learned English as their first language

- More than 75 different languages spoken in homes across the TDSB

- 17,415 permanent teachers

- 15,461 permanent support staff including teaching assistants, professional support workers, caretakers, maintenance staff, IT support, and administrators

- Approximately 3,500 occasional staff including teachers

School boards often boast about their diverse student population and the multiculturalism within their schools. Yet, if we are to address the needs of all students who require a wide range of support systems to reach their maximal potential and level of achievement, we cannot continue celebrating diversity and multiculturalism under the assumption that just because people from different parts of the world occupy the same space, it will autonomously lead to the establishment of inclusive learning environments through exposure to different cultures, languages, and sharing of unique cultural experiences (St. Denis, 2011; Kumashiro, 2004). Often within schools, multiculturalism is celebrated through the promotion of multicultural days and assemblies associated with themes where students gets the opportunity to wear their cultural clothes and bring in a sample dish from their culture to share with others. This form of superficial and passive cultural 
celebration is not enough to teach about difference and inequitable power relations in the context of the $21^{\text {st }}$ century, because all year round schools continue to operate under the one-size-fits-all curriculum and its hierarchical power relations which benefits certain identities at the expense of marginalization and exclusion to racialized and minoritized students (Tupper et al, 2008; Andreotti, 2006). As a consequence, lack of inclusion has lead to high dropout rates among specific populations including Caribbean and Latino students within the Toronto District School Board (Rodriguez, 2011). Focusing on altering teacher habitus as an area to foster higher levels of inclusion in the classroom has the potential to make a change by striving to address the needs of all students, particularly those who have been historically abandoned and systemically marginalized by the education system. As Kumashiro (2001) points out, "Anti-oppressive education involves constantly looking beyond what it is we teach and learn" (p. 6) and that this type of education "involves learning something different, learning something new, learning something that disrupts one's commonsense view of the world" (p. 8).

Numerous studies have pointed out the general benefits of international experience in terms of developing more global-minded teachers (Flournoy, 1994; Merryfield, 2000; Cushner, 2007; Rodriguez, 2011). Examples of such benefits include increased intercultural sensitivity, increased autonomy, and openness to cultural diversity. Yet, a critical examination of such benefits recognizes that an international experience alone does not equate to better and more inclusive teachers. It is the quality of the experience and how you process the experience that makes the difference in creating changes and new perspectives in connection to one's teaching practices. Factors such as the location, length of the trip, extent of formal and informal interactions with locals, and the objective of the trip are influential factors in what is gained from the experience. As Dewey (1938) points out in Experience and Education, "Everything depends upon the quality of experience which is had. The quality of any experience has two aspects. There is an immediate aspect of agreeableness or disagreeableness, and there is its influence upon later experiences" (p. 27). Dewey further expands on this by stating, "Every experience is a moving force. Its value can be judged only on the ground of what it moves toward and into" (p. 38). As it relates to the works of Bourdieu and his concept of habitus, the quality of an international experience for teachers can be evaluated and assessed by how it influences the teacher's habitus and his/her teaching practices within the classroom upon return from the experience.

An international experience in a non-Western country holds potential to disrupt the comfort level associated with teachers' habitus by sensitizing them to assumptions which have distorted their gaze through which they interpret the world and their interactions within it. Teachers are likely to develop a sense of critical consciousness (Freire, 1970) where they become aware of their assumptions and the stereotypes engrained in their subconscious as a result of constant exposure to biased narratives living in a Eurocentric society and teaching within a Eurocentric curriculum. Therefore, teacher assumptions and 
stereotypical beliefs can be shattered with direct, authentic contact and collective experiences with people from different cultures and ethnicities. This can lead teachers not to fear diversity but rather embrace it as a beauty and an asset to fostering cross-cultural learning and understanding. Upon return from their international experience, teachers can begin to view students as resources for learning. Rather than teaching to assimilate, teachers can transition to think of creative, critical ways where students can bring their culture and way of embodied being into the classroom in + a constructive manner that goes beyond superficial explorations. Working towards establishing a welcoming classroom atmosphere will help break down barriers and foster an inclusive learning environment, because everyone learns from one another rather than the hierarchical approach of exclusively the students learning from the teacher. Capitalizing on student's subcultures by welcoming it into the classroom and being open-minded towards it rather than judgemental can function as an important catalyst to motivate students and keep them engaged in what they are learning (Dei, 2000; Goldstein, 2003).

\section{Case Studies: Autobiographies}

For Bourdieu, his experiences in Algeria had a big influence on his character, research methods, and understanding of social issues. As Bourdieu (2004) states, "the transformation of my vision of the world that accompanied my transition from philosophy to sociology, of which my Algerian experience was without contest the pivotal moment" (p. 433). By interacting and having collective experiences with the locals in various capacities including being an associate professor at the University of Algiers, Bourdieu was able to learn about Algeria, its culture, value system, customs, and way of life. As a result, Bourdieu came to view Algerians in a completely different light than the image projected by France and its dominant discourse and hegemonic meta-narratives at the time. By experiencing the pain of the Algerian people by being amongst them, in some cases even risking his life to be with the local as part of their collective struggle to stand up to being oppressed, Bourdieu began understanding from a grassroots perspective why Algerians opposed being colonized and why they were fighting for their liberation. These life experiences, particularly in a non-Eurocentric context contributed to the development of Bourdieu's interdisciplinary approach to doing research, referred to as reflexive sociology, which combines the objective with the subjective in an attempt to bridge the gap between theory and lived experiences. As Bourdieu (1999) points out, "we must work with the multiple perspectives that correspond to the multiplicity of co-existing, and sometimes directly competing, points of view" as a means of arriving at new understandings (p. 3). Similarly, hooks (2003) states that, "Dislocation is the perfect context for free-flowing thought that lets us move beyond the restricted confines of a familiar social order" (p. 21). In other words, we must be willing to take risks and venture 
into the unknown and the unfamiliar as it has the potential to assist in us arriving at new perspectives and insights.

Spending time in a non-Western country whose language is not English will make teachers gain an understanding and appreciation for language as a form of linguistic capital. Teachers will directly experience what it feels like to struggle to be understood physically, psychologically, emotionally, and spiritually involving different senses. Teachers, in various unique contexts, will experience frustrations and negative emotions as a result of not fitting in and/or not being able to express their concerns in a common language. This experience will make them aware and conscious of how lack of mastery of the dominant language and culture and its power dynamics can impact their students, and how without encouragement and access to support systems, it can lead to disengagement from learning and caring about learning. Furthermore, teachers will likely formulate interconnections between linguistic capital and their assessment and evaluation practices, recognizing that too often assessments and evaluations are highly languagebased. This places immigrants and English as Second Language (ESL) learners at a great disadvantage, because as Bourdieu (1993) points out in The Linguistic Market, "in order for your words to 'count', you must not only say the grammatically correct words, but also the socially acceptable words (p. 79). Hence, many immigrant and ESL students get poor marks not because they do not understand the course material, but because they have difficulties expressing and articulating their ideas in a socially acceptable manner in written format (Goldstein, 2003). Therefore, an international experience in a non-Western country can trigger teachers to critically analyze their previously taken for granted assumptions about their preferred choice of assessments and evaluation techniques and its effectiveness in relation to the needs, skill levels, and background of their students. As Egbo (2011) states, teachers "must understand the need for adopting authentic approaches to assessment that have written, verbal and performance components in order to accommodate preferred learning styles, differential linguistic and communicative competence, as well as cultural backgrounds" (p.32).

There are numerous ways teachers can alter their classroom dynamics while keeping in mind linguistic capital. For example, teachers can begin by being more sensitive towards students and their individualistic needs within a framework that provides support and encouragement towards those displaying linguistic difficulties. Teachers can rely more on differentiated instruction to teach course contents. As well, teacher can provide options for students to demonstrate mastery of content or specific skills when giving out assignments. Complimentary to providing students with choices to demonstrate their learning, teachers can place less emphasis on grammar and consider other factors in marking such as effort and improvement over time. Assigning of students into groups for projects can be conducted keeping in mind differences in linguistic capital as well as their individual strengths and weaknesses. Lastly, teachers can explore creative ways of capitalizing on peer social capital, especially for students who speak the same language, 
as a means of assisting them in the learning process (Goldstein, 2003), rather than punishing and disadvantaging them for speaking another language in the classroom. Students who speak the same language can work together to empower each other by assisting in translation of words and encouraging one another in group settings.

As a Middle-Eastern male who immigrated to Canada at the age of ten from Iran, I had difficulties expressing my ideas and visions due to language barriers. I had finished up to grade three in Iran, and when I enrolled into the education system in Toronto, I had to adapt to a new learning environment consisting of different teaching styles, rules, and policies. Cultural differences and language barriers made school very difficult for me to the extent that I felt I did not belong. However, my passion for learning along with the help of supportive parents and encouragement from certain teachers who utilized inclusive teaching strategies and critical pedagogy allowed me to make a transition from ESL classes to a regular classroom within a short span of two years.

I remember vividly one of my elementary teachers constantly providing me with one-onone support before and after class as a means of encouraging me to continue to learn and work through the struggle. In one instance, she got me to write about the topic of winter in Farsi which was my mother tongue language and got another teacher who spoke the same language to translate it in order to understand my writing and what I was trying to express. After understanding how I had written about the hibernation of animals and the change in trees, she told me how in depth my work was and it painted a beautiful picture in her mind of the characteristics of winter. That moment itself engrained much confidence in me to believe in my thoughts and continue to express them even though at times I struggled in communicating my ideas clearly. This sort of sensitivity, acknowledgement, and effort on behalf of the teacher towards understanding me and finding avenues to allow me express my thoughts encouraged me to continue trying hard to master learning activities even though my marks were not improving drastically.

Fortunately, I had the blessing of being raised in an environment where assistance from teachers and mentors inspired me not to give up. Unfortunately, it is tragic that many students do not get the same opportunity that I was offered; an opportunity to progress his/herself to their full potential because they are not guided in a supportive and inclusive learning environment. This is why it is necessary to explore to what extent an international experience for teachers to a non-Western country holds potential to foster more effective teaching practices and inclusivity as a means of keeping students engaged in their schooling experiences and keeping the away from dropping out.

By being exposed to a different culture, customs, and value system, teachers can gain a more in-depth awareness and understanding of social issues in a culture-specific and unique political context. Teachers can then use this knowledge within their pedagogy to engage students from multiple vantage points. In 2011, I did a teaching internship in Barbados for three months as part of the York International Internship Program. Through 
my informal interactions with the local residents and the students in Barbados I learned that a high degree of homophobia exists in Bajan culture. Therefore, while conducting a diversity workshop for the students I guided them to examine the notion of sexual orientation. Numerous stereotypical comments were made expressing negative attitudes towards gays and lesbians. Expecting such reaction, I transitioned to raise questions to guide their thinking in an attempt to reposition their vantage point and perspectives, recognizing "deep cultural understanding cannot be guaranteed particularly if students are confined to their own cultural perspectives in making sense of differences" (Talburt \& Stewart, 1999 p. 173). This process involved examining presumptions about who is gay or lesbian, whether sexual orientation is decided by birth or by choice, and feelings and emotions felt by gay or lesbians as a result of being ostracized within a highly homophobic culture.

As a means of reinforcing examination of the issue from multiple perspectives, I shared my personal experiences with the class; having lived in a similar homophobic culture in Iran and transitioned to move to a diversified and multicultural environment in Toronto. I pointed out how a change in culture influenced me to critically examine my attitude and actions towards gays and lesbians. This cross-cultural reflection of my own experiences provided me with an overview of where I had started and how much I had grown in my outlook towards others in terms of socio-cultural understanding, specifically having become more open-minded and less judgemental. Egbo (2011) points out in What Should Preservice Teachers Know about Race and Diversity? Exploring a Critical Knowledge-Base for Teaching in 21st Century Canadian Classrooms that "understanding the teaching self involves a process of autobiographical analysis that should enable teachers to understand how their personal histories may intersect with their teaching practices (p. 28). Similarly, hooks (2003) emphasizes that "through the cultivation of awareness, through the decolonization of our minds, we have the tools to break with the dominator model of human social engagement and the will to imagine new and different ways that people might come together"(p. 35).

Having exposed and shared my own vulnerabilities, students became more comfortable discussing the issue and began to share personal stories of how they mistreated those who they assumed were gays and lesbians. I was not judgemental of such comments because as a child growing up in Iran I believed in similar stereotypes. As a means of repositioning their perspective through empathy, I posed a hypothetical question to the class; "If your brother or sister admitted to being gay or lesbian, would you love them any less?" Students admitted that they had not thought about it from that perspective since majority of them had never come in direct personal contact with someone who overtly admitted to being gay or lesbian. Yet, overall the consensus was that they would love their brother or sister regardless of their sexual orientation. 
Gaining an inside perspective into a different school system and its normative teaching practices and strategies can be beneficial to teachers as it provides them with a different point of reference to evaluate their own practices. Teachers can then begin to question the effectiveness of their teaching strategies and pedagogy as it relates to the needs, interests, and experiences of the students in their classrooms. While teaching students in Barbados, I often relied on hands-on activities to engage students and spark discussions about social issues. Students enjoyed this process yet pointed out that they were not accustomed to such pedagogy within their experience in the Barbados school system. They explained to me that teachers often lectured and that students were not given opportunities to have discussions or exchange ideas. Simply put, the word of the teacher was the law and not to be questioned. This reminded me of my own childhood experiences within the educational system in Iran. Having learned about how the education system operates in Barbados, I became more conscious of why certain students were shy to speak up and share their opinions; a consequence of being socialized within a completely different education system with its own authoritative norms and regulations. Overall, my experience in an unfamiliar school system taught me the importance of inquiring about the students' previous experiences and contextualizing it in relation to the surrounding socio-cultural and political conditions as a means of creating an inclusive learning environment where students can feel that they belong and that their stories, experiences, and opinions matter.

\section{Analysis \& Findings}

As Flournoy (1993) emphasizes, teachers must learn to "bring the world to students in a way that can be heard and understood" (p. 5). This indicates the importance of providing a voice for students within the classroom setting, more specifically providing mediums through which students can express their concerns, share their opinions and experiences, and learn from one another. The process begins with "a growing understanding of the importance of multicultural education and the needs to attend to individual differences in the learning process" (Cushner, 2009, p. 34). Appreciation of individual differences can be utilized by the teachers "to teach with, to work with, and continue to learn from people different from themselves" (p. 37). This process can be facilitated by altering/disrupting the teacher habitus through an international experience to non-Western country.

Although majority of studies focus on examining the positive aspects and experiences of teachers going abroad, some researchers (Merryfield, 2010; Rodrigues, 2011) argue that perhaps it is the intensive nature of teachers' negative experiences that leads to a paradigm shift in cross-cultural understanding; a shift from ethnocentrism to ethnorelativism. Merryfield (2000) conducted a qualitative analysis examining lived experiences of eighty teacher educators. Many of the teacher educators had their most profound 
experiences while living outside of their home country which involved an "experiential understanding of discrimination and outsider status" as it intersects with ideologies of power and privilege (p. 429). These experiences involved feelings of disorientation, confusion, and discomfort arising from being in new, unfamiliar situations without lack of accessibility to support systems. As a result of such experiences, teachers began to question and critically analyze various aspects of their identity within culture-specific contexts which were previously taken for granted including gender, race, and notions of power, status, and privilege.

For Toronto teachers who teach a Eurocentric curriculum, an international experience in a non-Western country can facilitate a better understanding of the historical roots and processes that contributes to normalizing of Whiteness and its privileges. As well, teachers will understand the impact of racism, its influence on self-esteem, and its carryover effects into the classroom as it relates to the motivation of students to participate and learn. Therefore, direct exposure to the stresses of dealing with ambiguity, of wanting to belong yet being an outsider, and the discomfort and insecurity of being treated different will sensitize teachers to these issues within their classroom as it relates to students' capacity for learning. Vivid memories from their international experience can enable teachers to empathize and to consequentially implement inclusive teaching strategies within their classrooms. As a result of their uncomfortable experience(s), teachers will more likely put greater efforts towards creating inclusive learning environments coupled with accessible support systems where students can feel safe being who they are and encouraged to take risks as part of the learning process to blossom their potential.

As Bourdieu (1999) points out, "space is one of the sites where power is asserted and exercised" (p. 126). Teachers assert their power in the classroom through classroom management and their everyday decisions. Exposure to a different school system and its power relations can influence teachers to imagine new possibilities and strategies as it relates to their decision making and its implications for students and their identities. Important questions may arise include; Is competition or cooperation promoted as a major theme in the classroom to encourage learning? What kind of reward system is implemented in the classroom as it relates to the use of language, mannerism, dress code, and way of being? Do opportunities exist for students to bring in their experiential knowledge and lived experiences into the classroom or is the learning predominantly guided by Eurocentric ideologies from print textbooks? These questions begin to acknowledge the relationships between power, organization of learning spaces, and identity of students.

Upon returning from my travels, as a teacher who was teaching grade ten Canadian History in a Toronto high school, I found it tragic how little content was devoted in the textbook to discussing Aboriginals and the injustices imposed on them by the Canadian 
government. The meta-narrative in the textbook downplayed the violence enacted upon the Aboriginals and painted a very Eurocentric one-dimensional linear narrative. As a means of encouraging students to look at the topic from a non-Eurocentric gaze, I created a group assignment where students had to examine the historical roots of Aboriginals through multiple perspectives, particularly having to look for indigenous sources and perspectives and their version of what took place historically. As a supplementary part to the assignment, students were encouraged to explore their own family and ancestral histories and share it with the class to the extent that they felt comfortable. This activity and teaching strategy was implemented in the spirit of cultivating racialized and minoritized cultural capital in the classroom as a means of empowering students, facilitating greater engagement between students, and a more indepth engagement with the social issues at hand.

\section{Conclusion \& Further Areas for Exploration}

Overall, my habitus as a student and a teacher has been drastically altered as a result of my life experiences in Iran, Canada, and Barbados. I am grateful that I have had the opportunity to live both within a non-Western, homogenous society of Iran and Barbados and the heterogeneous, multicultural society of Canada. Both experiences have had their share of joy and pain but they have extensively contributed to my growth as an educator including my values, ethics, character, and my teaching practices as a teacher. As I have transitioned to overcome many cultural and systemic barriers, I can confidently state that my past experiences have influenced and continue to shape my daily interactions with others. This process began with me learning and experiencing empathy through complexities of being a human in unfamiliar territories. The cross-cultural understanding that I gained by living within three different cultures sparked my passion to be a teacher, and to specifically work with "at-risk" youth because at some point in my life I was one of "them". Having vivid memories of such experiences, I always strive to create an inclusive learning environment where students do not lose interest in education due to systematic barriers but rather become encouraged to pursue education as a means of cultivating their true potential. For example, the experience of being an immigrant and an ESL student has made me sensitive and conscious of those in my class whom English is not their mother tongue. As a result, I attempt to provide students with options when it comes to assessment, give certain students more direct support ranging from extra attention and/or pairing with stronger students, and at times placing less emphasis on grammar and punctuation and more on the bigger picture such as whether or not a student understands the major ideas discussed.

In conclusion, although it is evident that teachers can experience personal and professional growth by going abroad, further research is needed to examine how such knowledge, skills, and understandings transfers to benefit students within their 
classrooms. Reflecting my own personal experiences and Pierre Bourdieu's time in Algeria, there seems to be a connection where an international experience in a nonWestern country holds potential for blossoming of new understandings as it relates to teacher development and establishment of inclusivity within classroom settings. Experiences in non-Western counties can alter teachers' habitus and equip them with a certain level of critical consciousness which includes "developing a deeper awareness of the self, broader perspectives about others and social issues, and seeing of one's potential and power to make a change within the classroom" (Cipolle, 2010, p. 7). This level of awareness and cross-cultural understanding, gained as a result of uncomfortable experiences within different cultures, will allow teachers to work towards deconstructing dominant meta-narratives within curriculum textbooks expressed as "natural" and "commonsense". The development of cross-cultural understanding can help educators foster inclusion in their classrooms by implementing teaching through multiple perspectives. This can lead to increasing the level of engagement amongst students, especially for students who often feel marginalized and silenced due to systematic and inequities of the education system.

Overall, exposure to the physical, psychological, and emotional challenges of being in a non-Western country holds potential to shift the teacher's gaze and alter his/her habitus to better understand students, their cultures, and lived experiences. In effect, this will more likely lead to the teacher being more reflexive and critically conscious of their teaching practices and the learning conditions within their classroom; taking into consideration the unique needs of the students in a context-specific manner, Further research into this field and area can provide new insights about how to engage students who have historically been disengaged within the North American education system. The findings ad implications can be used to plan more efficient teacher education programs, but more importantly to reach out to a greater number of students and improve the overall quality of education across all levels locally, nationally, and internationally.

\section{References}

Andreotti, V. (2006). Soft versus critical global citizenship education. Policy \& Practice: A Development Education Review, 3, 40-51.

Bourdieu, P. (1993). The linguistic market. Sociology in Question, London: Sage Publications.

Bourdieu, P. (1999). The weight of the world, Social suffering in contemporary society. Stanford University Press.

Bourdieu, P. (2004). Algerian landing, Ethnography. 5(4), 415-443. http://dx.doi.org/10.1177/1466138104048826

Cipolle, S. (2010). Service-learning and social justice, Engaging students in social change. United Kingdom: Rowman \& Littlefield Publishers Inc. 
Cushner. K. (2007). The role of experience in the making of internationally-minded teachers. Teacher Education Quarterly, 34 (1), 27-39.

Dei, G. (2000). Towards an anti-racism discursive framework. In Dei G. and Calliste A. (Eds.) Power, Knowledge, and Anti-Racism Education: A Critical Reader, Toronto: Fernwood Publishing Co.

Dewey, J. (1938). Experience and education. New York, NY: Kappa Delta Pi.

Egbo, B. (2011). What should preservice teachers know about race and diversity? Exploring a critical knowledge-base for teaching in 21 st century Canadian classrooms. Journal of Contemporary Issues in Education, 6 (2), 23-37.

Flournoy, M. (1993). Educating globally competent teachers. Paper presented at the Annual Meeting of the Council on International Educational Exchange. Washington, DC, 4 November, 1993.

Freire, P. (1970). Pedagogy of the oppressed. New York: The Continuum International Publishing Group Inc.

Goldstein, T. (2003). Contemporary bilingual life at a Canadian high school: Choices, risks, tensions, and dilemmas. Sociology of Education. 76, 247-264. http://dx.doi.org/10.2307/3108468

Hooks, b. (2003). Teaching community: A pedagogy of hope, New York: Routledge.

Horvat, E. (2001). Understanding equity and access in higher education: The potential contribution of Pierre Bourdieu. In Smart, J.C. and Tierney, W. (Eds.): Higher Education: Handbook of Theory and Research, 17, New York: Agathon Press.

Kumashiro, K. (2001). "Posts" perspectives on anti-oppressive education in Social Studies, English, Mathematics, and Science classrooms. Educational Researcher, 30(3), 3-12. http://dx.doi.org/10.3102/0013189X030003003

Kumashiro, K. (2004). Against common sense: Teaching and learning toward social justice. New York: Routledge.

Lareau, A. \& Weininger, W. (2003). Cultural capital in educational research: A critical assessment, Theory and Society, 32, 567-606. http://dx.doi.org/10.1023/B:RYSO.0000004951.04408.b0

Maton, K. (2008). Habitus. In Grenfell, M. (Eds.): Pierre Bourdieu Key Concepts, United Kingdom: Acumen Publishing Limited.

Merryfield, M. (2000). Why aren't teachers being prepared to teach for diversity, equity, and global interconnectedness? A study of lived experiences in the making of multicultural and global educators. Teaching and Teacher Education, 16, 429-443. http://dx.doi.org/10.1016/S0742-051X(00)00004-4

Portelli, J. \& Sharma, M. (2014). Uprooting and settling in: The invisible strength of deficit thinking, LEARNing Landscapes, 8(1), 251-267.

Reay, D., Davies, J., David, M. \& S. J. Ball (2001). Choices of degree or degrees of choice? Class, 'race' and the higher education choice process. Sociology. 35(4), 855-874. 
Reay, D. (2004). It's all becoming a habitus: Beyond the habitual use of habitus in educational research, British Journal of Sociology of Education. 25(4), 431-444. http://dx.doi.org/10.1080/0142569042000236934

Rodriguez, E. (2011). Reflections from an international immersion trip: New possibilities to institutionalize curriculum. Teacher Education Quarterly, 38(1), 147-160.

St. Denis, V. (2011). Silencing Aboriginal curricular content and perspectives through multiculturalism: There are other children here, Review of Education, Pedagogy \& Cultural Studies, 33(4), 306-317. http://dx.doi.org/10.1080/10714413.2011.597638

Talburt, S and M. Stewart. (1999). What's the subject of study abroad? Race, gender and "living culture", The Modern Language Journal, 83, 163-175. http://dx.doi.org/10.1111/0026-7902.00013

Tupper, J., \& Cappello, M. (2008). Teaching the treaties as (un)usual narratives: Disrupting the curricular commonsense. Curriculum Inquiry, 35(1), 559-578. http://dx.doi.org/10.1111/j.1467873X.2008.00436.X

Toronto District School Board. (2015). Quick Facts. At: < http://www.tdsb.on.ca/AboutUs/QuickFacts.aspx>. 